\title{
Testing for gluten-related disorders in clinical practice: The role of serology in managing the spectrum of gluten sensitivity
}

\author{
David Armstrong MA MB BChir FRCP(UK) FACG AGAF FRCPC ${ }^{1}$, \\ Andrew C Don-Wauchope MD MBBCh FRCPE FRCPC FRCPath ${ }^{2}$, Elena F Verdu MD PhD ${ }^{1}$
}

D Armstrong, AC Don-Wauchope, EF Verdu. Testing for gluten-related disorders in clinical practice: The role of serology in managing the spectrum of gluten sensitivity. Can J Gastroenterol 2011;25(4):193-197.

Immunoglobulin A tissue transglutaminase is the single most efficient serological test for the diagnosis of celiac disease. It is well known that immunoglobulin A tissue transglutaminase levels correlate with the degree of intestinal damage, and that values can fluctuate in patients over time. Serological testing can be used to identify symptomatic individuals that need a confirmatory biopsy, to screen at-risk populations or to monitor diet compliance in patients previously diagnosed with celiac disease. Thus, interpretation of serological testing requires consideration of the full clinical scenario. Antigliadin tests are no longer recommended for the diagnosis of classical celiac disease. However, our understanding of the pathogenesis and spectrum of gluten sensitivity has improved, and gluten-sensitive irritable bowel syndrome patients are increasingly being recognized. Studies are needed to determine the clinical utility of antigliadin serology in the diagnosis of gluten sensitivity.

Key Words: Antigliadin antibodies; Antitissue transglutaminase; Celiac disease; Diagnosis; Gluten intolerance; Serology
Le dépistage des troubles liés au gluten en pratique clinique : le rôle de la sérologie dans la prise en charge du spectre de sensibilité au gluten

La transglutaminase tissulaire de l'immunoglobuline A est le test sérologique le plus efficace pour diagnostiquer la maladie cœliaque. Il est bien connu que les taux de transglutaminase tissulaire de l'immunoglobine A sont corrélés au degré de lésion intestinale et que les valeurs peuvent fluctuer chez les patients au fil du temps. Le test sérologique peut permettre de repérer les personnes symptomatiques qui ont besoin d'une biopsie de confirmation, de dépister les populations à risque ou de surveiller le respect du régime alimentaire chez les patients ayant déjà un diagnostic de maladie coliaque. Ainsi, pour interpréter le test sérologique, il faut envisager l'ensemble du scénario clinique. Les tests d'antigliadine ne sont plus recommandés pour diagnostiquer une maladie cœliaque classique. Cependant, on comprend mieux la pathogenèse et le spectre de la sensibilité au gluten, et on dépiste de plus en plus les patients atteints du syndrome du côlon irritable sensible au gluten. Des études s'imposent pour déterminer l'utilité clinique de la sérologie antigliadine dans le diagnostic de sensibilité au gluten.
$\mathrm{T}$ here is an evolving paradigm shift in our understanding of glutenrelated disorders. The prevailing concept had been that one should be able to distinguish between patients who had celiac disease - the gluten-related disorder - and those who did not. In this disease model, patients with 'classical' or 'typical' celiac disease have gluteninduced, immune-mediated injury to the small bowel mucosa leading to villous atrophy and, hence, to malabsorption manifesting as diarrhea, abdominal pain, weight loss and anemia. Small bowel biopsy, achieved endoscopically in recent years, was considered to be the 'gold standard' for the diagnosis of celiac disease (1). However, endoscopy and duodenal biopsy are cumbersome, uncomfortable and expensive. The advent of serological tests, therefore, offered the welcome opportunity of diagnosing celiac disease without the need for endoscopy. Serology has been compared with and validated against duodenal histology for the diagnosis of celiac disease. That is, serology has been viewed as a surrogate for histological diagnosis of gluten-related disease based on the assumptions that villous atrophy is pathognomonic of celiac disease and that celiac disease is the only manifestation or, at least, the only clinically significant manifestation of a gluten-related disorder. This has led to a view that there must be a 'best' or 'optimal' serological marker for gluten-related disease. The present review discusses the clinical use of serology when clinical and histological findings are consistent with a straightforward diagnosis of celiac disease. However, it is important to recognize that 'borderline' clinical scenarios will be common in clinical practice. Testing for gluten-related disease and, in particular, the interpretation of serological test results should, therefore, be informed by supportive evidence that gluten can induce - in susceptible individuals - a multisystem autoimmune disorder with protean manifestations that respond to strict dietary intervention. Diet-related improvements will affect not only the duodenal mucosa and gastrointestinal symptoms but also, to a greater or lesser extent, dermatological, neurological and hematological manifestations, as well as bone health, quality of life and mortality (2). The presence of marked villous atrophy (Marsh grade III or IV) (3) or a particular serological marker is highly unlikely to be the sole indicator of whether an individual has gluten-related disease. It is, therefore, critical to use serological tests in the context of the clinical question that is being asked and to interpret them in the context of the pathophysiological process that is being treated (Table 1).

\footnotetext{
${ }^{1}$ Farncombe Family Digestive Health Research Institute and Division of Gastroenterology; ${ }^{2}$ Department of Pathology and Molecular Medicine and

Department of Medicine, McMaster University, Hamilton, Ontario

Correspondence: Dr Elena F Verdu, Farncombe Family Digestive Health Research Institute and Division of Gastroenterology, McMaster University,

1200 Main Street West, Hamilton, Ontario L8N 325. Telephone 905-525-9140 ext 20051, fax 905-521-3454, e-mail verdue@mcmaster.ca

Received for publication October 6, 2010. Accepted October 10, 2010
} 


\begin{tabular}{|c|c|c|c|}
\hline $\begin{array}{l}\text { Clinical presentation } \\
\text { (gastrointestinal, } \\
\text { extraintestinal } \\
\text { or skin) }\end{array}$ & $\begin{array}{l}\text { Serology } \\
\text { (tTG) }\end{array}$ & Histology & Diagnosis \\
\hline Positive or silent & Positive & Positive & $C D$ \\
\hline Positive & Positive & Negative & Potential CD \\
\hline Positive & Negative & Positive & Seronegative $C D^{*}$ \\
\hline Positive & Borderline & Marsh I and II & Possible $\mathrm{CD}^{\dagger}$ \\
\hline Positive (skin) & Positive & $\begin{array}{l}\text { Positive or } \\
\text { negative }\end{array}$ & Dermatitis herpetiformis \\
\hline Positive & Negative & $\begin{array}{l}\text { Negative or } \\
\text { Marsh I }\end{array}$ & $\begin{array}{l}\text { Gluten-sensitive } \\
\text { IBS }^{\ddagger}\end{array}$ \\
\hline
\end{tabular}

General recommendations are useful but do not encompass the complexity of celiac disease (CD) and other gluten-related disorders. The table presents guidelines for the interpretation of some clinical scenarios associated with gluten-related disorders. *Positive human leukocyte antigen typing, immunoglobulin (Ig) A deficiency (positive IgG-class celiac antibodies); ${ }^{\dagger}$ Additional testing may be required: Positive IgA tissue transglutaminase (tTG) in intestinal biopsy; ${ }^{\ddagger}$ Positive antigliadin antibody test may help identify subgroups of patients with abdominal symptoms that improve on gluten-restricted diet. IBS Irritable bowel syndrome

\section{CLINICAL CONDITIONS ASSOCIATED WITH} ABNORMAL SEROLOGICAL TESTS FOR CELIAC DISEASE: THE SPECTRUM OF GLUTEN SENSITIVITY

Gluten-related disease is complex and incompletely understood. In clinical practice, one may encounter a variety of presentations including the following:

- 'Classical' or 'typical' celiac disease - high risk (4): Individuals who present with one or more symptoms including diarrhea, abdominal pain, anemia, malabsorption and weight loss.

- 'Classical' or 'typical' celiac disease - low risk (4): Individuals who present with abdominal pain and disturbed bowel habit (often diarrhea). This presentation has features of typical, high-risk celiac disease but the symptoms are often more suggestive of irritable bowel syndrome (IBS-D, IBS-mixed or, even IBS-C), and there is often no weight loss or other alarming features.

- 'Atypical', 'asymptomatic' or 'silent' celiac disease (5): Individuals who may have no gastrointestinal symptoms but experience extragastrointestinal manifestations of the gluten-mediated autoimmune process including dermatitis herpetiformis, irondeficiency anemia, osteopenia, gluten ataxia or small neural fibre disease.

- 'Asymptomatic' celiac disease - high risk (5): Individuals who complain of no symptoms, but who are at an increased risk because of a family history of celiac disease, or a personal history of diabetes mellitus or Down's syndrome.

- 'Partially treated' celiac disease - before or after formal diagnosis: Individuals who experience persistent symptoms despite management with a gluten-free diet (ie, 'refractory' celiac disease) or who may have treated themselves before formal diagnosis.

- 'Gluten sensitivity' (6): Individuals, with or without symptoms, who have no intestinal villous atrophy but who may exhibit a mucosal lymphocytic infiltrate after gluten challenge (Marsh I) $(7,8)$ or a symptomatic improvement after initiating a gluten-free $\operatorname{diet}(9,10)$.

- Other bowel and immunological conditions associated with detectable gliadin antibodies: This includes a range of immunoglobulin (Ig) G, increasing gastrointestinal pathologies, IgA excess conditions, such as IgA glomerulopathy, and immunological conditions such as rheumatoid arthritis (RhA).
TABLE 2

Diagnostic performance of available serological tests for classical celiac disease

\begin{tabular}{lccl}
\hline Test & Sensitivity, \% & Specificity, \% & References \\
\hline AGA-IgA & $46-87$ & $70-98$ & $10,46-49$ \\
AGA-IgG & $42-93$ & $84-97$ & $10,46-48,50$ \\
EMA $^{*}$ & $74-100$ & $99-100$ & $48-54$ \\
IgA-tTG $^{\dagger}$ & $81-100$ & $97-99$ & $48,51,55,56$ \\
IgG-tTG $^{\text {IgA-DGP }}$ & $27-100$ & $77-95$ & $10,50,57$ \\
IgG-DGP & $75-78$ & $95-100$ & 57,58 \\
\hline
\end{tabular}

*Monkey and human; 'Human. AGA Antigliadin antibody; DGP Deaminated gliadin peptide; EMA Endomysial antibody; Ig Immunoglobulin; tTG Tissue transglutaminase

\section{SCREENING AND DIAGNOSIS FOR GLUTEN-} RELATED DISORDERS USING SEROLOGICAL TESTS

Historically, screening for celiac disease was performed with a diagnostic test for malabsorption (D-xylose) or serological tests for antigliadin antibodies (AGA) and antiendomysial antibodies (anti-EMA). Antitissue transglutaminase (anti-tTG) tests followed and, more recently, antideaminated gliadin peptide (DGP) antibodies have been introduced (Table 2). These serological tests have become invaluable in the identification, diagnosis and management of patients with gluten-sensitive disorders that affect the bowel or the skin. The ability of human leukocyte antigen (HLA) typing for HLA-DQ2 and HLA-DQ8 associations with celiac disease to exclude disease is well described but not often used clinically.

Diagnostic test accuracy has shown that the AGA tests are less sensitive and less specific than EMA and tTG (11) to diagnose celiac disease. Sensitivity for the AGA-IgA test is in the range of $46 \%$ to $87 \%$, with a specificity of $70 \%$ to $98 \%$. The AGA-IgG test has sensitivity from $42 \%$ to $93 \%$, and specificity in the region of $84 \%$ to $97 \%$. However, a systematic review (12) revealed many issues related to heterogeneity in this test group.

Early in the decade, tests for DGP were described. These tests are derived from the understanding that the deamidation of gluten by tTG makes gliadin peptides more potent activators of T-cells in celiac disease patients (13). DGPs are formed by the action of tTG on gliadin. Both IgG and IgA tests are available. A number of commercial ELISA tests have been made available for research studies and are beginning to appear in the test menu of some clinical laboratories. Diagnostic test accuracy for DGP-IgA is not better than tTG-IgA, with pooled sensitivity of $87.8 \%$ (range $85.6 \%$ to $89.9 \%$ ) and specificity of $94.1 \%$ (range $92.5 \%$ to $95.6 \%$ ) (14). However, there is some preliminary data indicating that the DGP-IgG test may become a useful test in IgA deficiency $(15,16)$. Sensitivity for DGP-IgG is reasonable, with results between $69 \%$ and $81 \%$, while specificity is excellent, with results between $97.8 \%$ and $99.6 \%$. The diagnostic accuracy of DGP-IgA does not outperform tTG-IgA (17). Until now, there are no recommendations that $\mathrm{tTG}$ tests be replaced by DGP-AGA, but these tests may aid in the diagnosis of patients who are symptomatic and seronegative for tTG, and in children younger than two years of age. The use of the IgG DGP-AGA seems to be gaining support in the literature in both adults and pediatric populations $(18,19)$. The diagnostic utility of DGPs will require further investigation.

The pathophysiology of gluten-related disorders and serological testing

The various serological tests for celiac disease relate to different aspects of the pathophysiological process, whereby exposure of the gastrointestinal tract to dietary gluten leads to the development of antibodies (IgA and $\operatorname{IgG}$ ) against gliadin. In addition, however, there is the development of antibodies to host tTG (tTG-IgA and tTG-IgG). Host tTG is the antigen also recognized by EMA, which subsequently 
forms the basis for another serological test. More recent work has led to the development of serological tests that can identify antibodies to deamidated gliadin - the product of tTG action on dietary gliadin. Additional blood tests will help clarify the results of serological tests, either by determining whether a test may be falsely negative because the patient is IgA deficient, or whether the patient has a high pretest probability of gluten-related disease based on the presence of HLA-DQ2 or HLA-DQ8 genes.

Although histology is considered to be the 'gold standard' for the diagnosis of gluten-related disease, the degree of gluten-related injury ranges from Marsh I to Marsh IV. However, the severity of glutenrelated injury may vary from one biopsy to another, and only Marsh stages III and IV have generally been considered to be diagnostic of celiac disease. Thus, patients may experience less severe histological changes that are, nonetheless, gluten related. Under these circumstances, they will not be considered to have a 'gluten-related disorder', and a positive serological test will be considered to have been 'falsely positive'. It is important to note that younger patients with positive serology and no histological changes, as well as those who have only Marsh I and Marsh II changes, have all been shown to have increased morbidity and mortality rates compared with healthy controls $(2,20,21)$. Although increased mortality was not confirmed in a study of elderly individuals with undiagnosed celiac disease (22), a limited increase in morbidity related to reduced bone density was observed.

\section{Serological tests: Variability in celiac disease}

All of the tests mentioned above are used to diagnose celiac disease. The specificities and sensitivities reported are usually derived from studies using duodenal histology as the diagnostic gold standard. All of the serological tests have some degree of limitation from a laboratory perspective. First, there are no universal standards for the target antibodies. Second, each type of test (ELISA, radioimmuno assay and immunofluorescent assay) has high variability within lots, among lots and among methods. This variability makes the clinical interpretation more challenging when sequential results are compared. This was highlighted in a recent report from an international proficiency survey (23).

\section{Use of celiac serology tests in other conditions}

In addition to celiac disease, there are several well-described conditions that have been reported in association with positive AGA-IgA and AGA-IgG tests, although it remains to be proven whether any or all of these conditions are caused by gluten exposure.

IBS: Routine serological screening is now recommended for celiac disease in patients with IBS symptoms, particularly those with diarrheapredominant and mixed phenotypes of IBS (24,25). A positive IgA-tTG test will identify celiac disease as a potential cause of symptoms in a patient presenting with IBS symptoms. In the event of a positive biopsy, the patient will be diagnosed with celiac disease, and likely no longer considered to have IBS. However, a different clinical problem presents to the physician when a patient describes IBS-like symptoms that are triggered by gluten ingestion and improved after dietary exclusion, but who has a negative tTG and a normal or borderline biopsy (6). Serological testing using anti-AGA in these patients may help identify gluten sensitivity in patients who do not fulfill the diagnostic criteria for 'classic' celiac disease but who may, nonetheless, benefit from a gluten-exclusion diet $(6,9)$.

Dyspepsia: No significant association has been reported between dyspepsia and positive serological tests for antibodies to gliadin, tTG or endomysium. Although positive serology was found in $7.9 \%$ of patients with dyspepsia in one study (26), there was a $3.9 \%$ positivity rate in the controls. Thus, the current data do not support routine serology screening for gluten-related disorders in patients with dyspepsia.

Liver disease: The prevalence of celiac disease ranges from $1.5 \%$ to $9.0 \%$ in patients with elevated transaminase levels of unknown cause, from $2.9 \%$ to $6.4 \%$ in patients with autoimmune hepatitis, and up to $6.0 \%$ in those with primary biliary cirrhosis $(27,28)$. Thus, screening for celiac disease in patients with liver disease should be considered.
Inflammatory bowel disease (IBD): The prevalence of IBD in celiac disease, as diagnosed by AGA, EMA and tTG antibodies, and total IgA level, is increased 10-fold compared with that in healthy individuals whose serology was negative, while the prevalence of celiac disease in IBD patients was comparable with that in controls (29).

Other conditions reported to be associated with positive AGA serology: A higher prevalence of positive AGA serology has been reported in patients with RhA (30), Sjogren's syndrome (31), systemic lupus erythematosus, sarcoidosis and type 1 diabetes (32-34). Dermatitis herpetiformis is a well-recognized, gluten-sensitive skin disorder associated with a positive tTG test. There have also been reports of an association between celiac markers and pemphigoid (35) and atopic eczema (36). IgA nephropathy has also been associated with positive AGA serology (37).

\section{GENETIC TESTING FOR CELIAC DISEASE}

Two HLA class II molecules, HLA-DQ2 and HLA-DQ8, were associated with celiac disease circa 1990. It appears that approximately $90 \%$ of people with celiac disease have HLA-DQ2 and almost all the others carry HLA-DQ8. Other non-HLA genes have been described but none have been well characterized. A recent meta-analysis (38) suggested evidence for linkage at the telomeric region of chromosome 10 (10q26.12qter) and on chromosome 8 (8q22.2-q24.21). Most of these studies compared genetic data with biopsy-proven celiac disease.

Genetic testing can help to exclude celiac disease when used in combination with other serological tests. However, HLA typing is costly and not always readily available. Moreover, multicentre trials have shown that $0.4 \%$ of patients with celiac disease are both HLA-DQ2 and HLA-DQ8 negative (39). Thus, although nearly all celiac disease patients have one or more HLA associations, genotyping is still not recommended for routine testing because these are reasonably prevalent associations in the general population (ie, HLA-DQ2 in approximately 30\%).

\section{WHAT IS THE CLINICAL QUESTION BEING ASKED WHEN CELIAC SEROLOGY IS ORDERED?}

Serological testing for classical celiac disease is performed to identify symptomatic individuals who require a small intestinal biopsy; to screen asymptomatic individuals genetically at risk; and to monitor diet adherence in individuals that were already diagnosed with celiac disease.

- 'Classical' or 'typical' celiac disease: A positive IgA-tTG test should be followed by endoscopic biopsy because it remains the accepted method to 'confirm' classical celiac disease. EMA can be used to confirm the positive tTG test. If clinical suspicion is high and tTG is negative, an anti-EMA (particularly an IgG or covalent IgA and IgG) test will provide good diagnostic information. The new test for IgG-DGP demonstrates very high specificity (similar to tTG and EMA) and could replace EMA after tTG.

- Exclusion diagnosis of celiac disease: HLA typing can be used, but the test is expensive and not readily available.

- Screening: Asymptomatic, at-risk individuals may be screened for celiac disease if genetic susceptibility is present. This is generally based on a positive family history of celiac disease or associated autoimmune disorders such as type 1 diabetes. Because tTG levels correlate with the severity of intestinal injury (40), and tTG levels fluctuate in an individual over time, multiple antibody determinations are required. It has been suggested that repeat tTG and/or EMA testing should occur every two years in the at-risk population (41). Quantitative assessment of antibody titres may guide the physician as to the appropriate timing to indicate a biopsy.

- Monitoring of patients' adherence and response to a gluten-free diet: Repeat tTG testing in patients diagnosed with celiac disease and managed with a gluten-free diet is not indicated to confirm 
response to treatment. Studies have shown that tTG quantitative results will change with a gluten-free diet (42), but there is no evidence to suggest that regular, continued monitoring of tTG titres improves outcomes.

- Investigation of patients with IBS symptoms: A positive tTG test will identify patients who present clinically with IBS who, in fact, have underlying celiac disease, which is confirmed after endoscopic biopsy. If the patient has a negative tTG or a positive tTG with inconclusive histology, raised AGA levels may indicate whether there is any evidence of an immune response to gluten that implicates a role for gluten in producing symptoms. Conversely, negative AGA serology may demonstrate, with some certainty, that the patient's symptoms are not indicative of an autoimmune, gluten-related disorder. Further work is needed to more clearly elucidate the relationship between gastrointestinal symptoms and positive tTG, AGA and EMA.

\section{Is there a role for AGA serology in clinical gastroenterology practice?}

The identification and testing for AGA enabled the improved detection and management of patients with celiac disease. As our understanding of the pathogenesis and spectrum of gluten-related disorders improved, more accurate diagnostic testing became available for celiac disease. It is interesting to note that there is a wide range of conditions represented in the category of abnormal AGA testing. It should be acknowledged that there is a relatively high prevalence of these antibodies in the normal population (4\%) (43). Thus, some associations may, in fact, reflect a sampling error. However, a proportion of patients with IBS (negative tTG, with or without borderline enteropathy [Marsh I]) may respond

\section{REFERENCES}

1. Hill ID, Dirks MH, Liptak GS, et al. Guideline for the diagnosis and treatment of celiac disease in children: Recommendations of the North American Society for Pediatric Gastroenterology, Hepatology and Nutrition. J Pediatr Gastroenterol Nutr 2005;401-19.

2. Rubio-Tapia A, Kyle RA, Kaplan EL, et al. Increased prevalence and mortality in undiagnosed celiac disease. Gastroenterology 2009;137:88-93.

3. Marsh MN. Gluten, major histocompatibility complex, and the small intestine. A molecular and immunobiologic approach to the spectrum of gluten sensitivity ('celiac sprue'). Gastroenterology 1992;102:30-45.

4. Hopper AD, Cross SS, Hurlstone DP, et al. Pre-endoscopy serological testing for coeliac disease: Evaluation of a clinical decision tool. BMJ 2007;334:729.

5. Green PH, Jabri B. Celiac disease. Annu Rev Med 2006;57:207-21.

6. Verdu EF, Armstrong D, Murray JA. Between celiac disease and irritable bowel syndrome: The "no man's land" of gluten sensitivity. Am J Gastroenterol 2009;104:1587-94.

7. Troncone R, Franzese A, Mazzarella G, et al. Gluten sensitivity in a subset of children with insulin dependent diabetes mellitus. Am J Gastroenterol 2003;98:590-5.

8. Niveloni S, Dezi R, Pedreira S, et al. Gluten sensitivity in patients with primary biliary cirrhosis. Am J Gastroenterol 1998;93:404-8.

9. Wahnschaffe U, Ullrich R, Riecken EO, Schulzke JD. Celiac disease-like abnormalities in a subgroup of patients with irritable bowel syndrome. Gastroenterology 2001;121:1329-38.

10. Wahnschaffe U, Schulzke JD, Zeitz M, Ullrich R. Predictors of clinical response to gluten-free diet in patients diagnosed with diarrhea-predominant irritable bowel syndrome. Clin Gastroenterol Hepatol 2007;5:844-50.

11. AGA Institute medical position statement on the diagnosis and management of celiac disease. Gastroenterology 2006;131:1977-80.

12. Rostom A, Dubé C, Cranney A, et al. The diagnostic accuracy of serologic tests for celiac disease. Gastroenterol 2005;128(Suppl 1): S38-S46.

13. Alaedini A, Green PH. Autoantibodies in celiac disease. Autoimmunity 2008;41:19-26.

14. Lewis NR, Scott BB. Meta-analysis: Deamidated gliadin peptide antibody and tissue transglutaminase antibody compared as screening tests for celiac disease. Alim Pharmacol Ther 2010;31:73-81. symptomatically to gluten exclusion $(6,10)$. Thus, although AGA tests are no longer routinely recommended for the diagnosis of classical celiac disease because of their lower sensitivity and specificity, they may prove to be useful in gluten-sensitive patients with a clinical presentation of IBS. However, further investigation is warranted before firm recommendations can be made regarding the use of AGA serology for the diagnosis of gluten sensitivity.

\section{CONCLUSIONS}

Anti-tTG testing is highly sensitive and specific for celiac disease, and remains the single serological test of choice for diagnosing and screening for celiac disease. Although the various commercial assays have different parameters, overall, they perform fairly well at detecting celiac disease. It is important to keep in mind that tTG antibody levels fluctuate and depend on the degree of intestinal damage. Thus, a negative test is possible in a patient with minimal pathology (ie, Marsh I lesion) and does not necessarily rule out milder forms of celiac disease. Repeat testing may provide significant clinical insight and help decide the appropriate timing for a biopsy or monitoring dietary compliance.

Perhaps a parallel can be drawn between the diagnostic approach to celiac disease, as a gluten-related disorder, and other multisystem inflammatory diseases with autoimmune components such as RhA. For instance, rheumatologists recognize that RhA may manifest primarily by virtue of its effects on the joints. However, it is a systemic disease with various serological markers; the most recently adopted classification criteria (44) incorporate these markers. It may be useful to consider a similar approach to celiac disease, based on fulfillment of a number of diagnostic criteria that include typical symptoms, positivity of serology at high titre, enteropathy and response to a glutenfree diet (45).

15. Villalta D, Tonutti E, Prause C, et al. Diagnostic performance of IgG anti-deamidated gliadin peptide antibody assays is comparable to IgA anti-tTG in celiac disease. Clin Chem 2010;56:464-8.

16. Vermeersch P, Geboes K, Mariën G, Hoffman I, Hiele M, Bossuyt X. IgG antibodies against deamidated gliadin peptides for diagnosis of celiac disease in patients with IgA deficiency. Clin Chim Acta 2010;411:931-5.

17. Lewis NR, Scott BB. Systematic review: The use of serology to exclude or diagnose coeliac disease (a comparison of the endomysial and tissue transglutaminase antibody tests).

Aliment Pharmacol Ther 2006;24:47-54.

18. Volta U, Granito A, Parisi C, et al. Deamidated gliadin peptide antibodies as a routine test for celiac disease: A prospective analysis. J Clin Gastroenterol 2010; 44:186-90.

19. Basso D, Guariso G, Fogar P, et al. Antibodies against synthetic deamidated gliadin peptides for celiac disease diagnosis and follow-up in children. Clin Chem 2009;55:150-7.

20. Ludvigsson JF, Montgomery SM, Ekbom A, Branst L, Granath F. Small intestinal histopathology and morality risk in celiac disease. JAMA 2009;302:1171-8.

21. Green PH. Mortality in celiac disease, intestinal inflammation, and gluten sensitivity. JAMA 2009;302:1225-6.

22. Godfrey JD, Brantner TL, Brinjikji W, et al. Morbidity and mortality among older individuals with undiagnosed celiac disease. Gastroenterology 2010;139:763-9.

23. Li M, Yu L, Tiberti C, Bonamico M, et al. A report on the International Transglutaminase Autoantibody Workshop for Celiac Disease. Am J Gastroenterol 2009;104:154-63.

24. Brandt LJ, Chey WD, Foxx-Orenstein AE, et al; American College of Gastroenterology Task Force on Irritable Bowel Syndrome. An evidence-based position statement on the management of irritable bowel syndrome. Am J Gastroenterol 2009;104(Suppl 1):S1-35.

25. Ford AC, Chey WD, Talley NJ, Malhotra A, Spiegel BM, Moayyedi P. Yield of diagnostic tests for celiac disease in individuals with symptoms suggestive of irritable bowel syndrome: Systematic review and meta-analysis. Arch Intern Med 2009;169:651-8.

26. Locke GR 3rd, Murray JA, Zinsmeister AR, Melton LJ III, Talley NJ. Celiac disease serology in irritable bowel syndrome and dyspepsia: 
A population-based case-control study. Mayo Clin Proc 2004;79:476-82.

27. Lo lacono O, Petta S, Venezia G, et al. Anti-tissue transglutaminase antibodies in patients with abnormal liver tests: Is it always coeliac disease? Am J Gastroenterol 2005;100:2472-7.

28. Mirzaagha F, Azali SH, Islami F, et al. Coeliac disease in autoimmune liver disease: A cross-sectional study and a systematic review. Dig Liver Dis 2010;42:620-3.

29. Leeds JS, Höroldt BS, Sidhu R, et al. Is there an association between coeliac disease and inflammatory bowel diseases? A study of relative prevalence in comparison with population controls. Scand J Gastroenterol 2007;42:1214-20.

30. Koot VC, Van Straaten M, Hekkens WT, Collee G, Dijkmans BA. Elevated level of IgA gliadin antibodies in patients with rheumatoid arthritis. Clin Exp Rheumatol 1989;7:623-6.

31. Teppo AM, Maury CP. Antibodies to gliadin, gluten and reticulin glycoprotein in rheumatic diseases: Elevated levels in Sjögren's syndrome. Clin Exp Immunol 1984;57:73-8.

32. Rensch MJ, Szyjkowski R, Shaffer RT, et al. The prevalence of celiac disease autoantibodies in patients with systemic lupus erythematosus. Am J Gastroenterol 2001;96:1113-5.

33. McCormick PA, Feighery C, Dolan C, et al. Altered gastrointestinal immune response in sarcoidosis. Gut 1988;29:1628-31.

34. Calero P, Ribes-Koninckx C, Albiach V, Carles C, Ferrer J. IgA antigliadin antibodies as a screening method for nonovert celiac disease in children with insulin-dependent diabetes mellitus. J Pediatr Gastroenterol Nutr 1996;23:29-33.

35. Leonard JN, Fry L, Wright P, et al. Gliadin in bullous pemphigoid. Lancet 1981;2:1111-2.

36. Finn R, Harvey MM, Johnson PM, Verbov JL, Barnes RM. Serum IgG antibodies to gliadin and other dietary antigens in adults with atopic eczema. Clin Exp Dermatol 1985;10:222-8.

37. Rostoker G, Delprato S, Petit-Phar M, et al. IgA antigliadin antibodies as a possible marker for IgA mesangial glomerulonephritis in adults with primary glomerulonephritis. N Eng J Med 1989;320:1283-4.

38. Forabosco P, Neuhausen SL, Greco L, et al. Meta-analysis of genome-wide linkage studies in celiac disease. Hum Hered 2009;68:223-30.

39. Karell K, Louka AS, Moodie SJ, et al. HLA types in celiac disease patients not carrying the DQA $1 * 05-\mathrm{DQB} 1 * 02$ (DQ2) heterodimer: Results from the European Genetics Cluster on Celiac Disease. Hum Immunol 2003;64:469-77.

40. Green PH, Rostami K, Marsh MN. Diagnosis of coeliac disease. Best Pract Res Clin Gastroenterol 2005;19:389-400.

41. Bonamico M, Ferri M, Mariani P, et al. Serologic and genetic markers of celiac disease: A sequential study in the screening of first degree relatives. J Pediatr Gastroenterol Nutr 2006;42:150-4.

42. Tonutti E, Visentini D, Bizzaro N, et al; French-Italian Laboratory Study Group on Coeliac Disease. The role of antitissue transglutaminase assay for the diagnosis and monitoring of coeliac disease: A French-Italian multicentre study. J Clin Pathol 2003;56:389-93.

43. Barnes RM, Barton PG, Doig JE, Finn R, Harvey MM, Johnson PM. Distribution of serum antibodies to wheat gliadin and bovine milk in atopic and non-atopic healthy adults. J Clin Lab Immunol 1983;12:175-8.

44. Aletaha D, Neogi T, Silman AJ, et al; American College of Rheumatology; European League Against Rheumatism. 2010 rheumatoid arthritis classification criteria: An American College of Rheumatology/European League Against Rheumatism collaborative initiative. Arthritis Rheum 2010;62:2569-81.

45. Catassi C, Fasano A. Celiac disease diagnosis: Simple rules are better than complicated algorithms. Am J Med 2010;123:691-3.

46. Bode S, Gudmand-Hoyer E. Evaluation of the gliadin antibody test for diagnosing celiac disease. Scand J Gastroenterol 1994;29:148-52.

47. Rashtak S, Ettore MW, Homburger HA, Murray JA. Comparative usefulness of deamidated gliadin antibodies in the diagnosis of celiac disease. Clin Gastroenterol Hepatol 2008:6:426-32

48. Tesei N, Sugai E, Vázquez H, et al. Antibodies to human recombinant tissue transglutaminase may detect celiac patients undiagnosed by endomysial antibodies. Alim Pharmacol Ther 2003;17:1415-23.

49. Valdimarsson T, Franzen L, Grodzinsky E, Skogh T, Ström M. Is small bowel biopsy necessary in adults with suspected celiac disease and IgA anti-endomysium antibodies? Dig Dis Sci 1996;41:83-7.

50. Yagil Y, Goldenberg I, Arnon R, Ezra V, Ashkenazi I. Serologic testing for celiac disease in young adults. Dig Dis Sci 2005;50:796-805.

51. Carroccio A, Vitale G, Di Prima L, et al. Comparison of anti-transglutaminase ELISAs and an anti-endomysial antibody assay I the diagnosis of celiac disease. Clin Chem 2002;48:1546-50.

52. Dickey W, McMillan SA, McCrum EE, et al. Association between serum levels of total IgA and IgA class endomysial and anti-gliadin antibodies. Eur J Gastroenterol Hepatol 1997;9:559-62.

53. Dickey W, McMillan SA, Hughes DF. Identification of celiac disease in primary care. Scand J Gastroenterol 1998;33:491-3.

54. Shahbazkhani B, Forootan M, Merat S, et al. Coeliac disease presenting with symptoms of irritable bowel syndrome. Alim Pharmacol Ther 2003:18:231-5.

55. Hadithi M, von Blomberg BM, Crusius JB, et al. Accuracy of serologic tests and HLA-DQ typing for diagnosing celiac disease. Ann Intern Med 2007;147:294-302.

56. Catassi C, Kryszak D, Louis-Jacques O, et al. Detection of celiac disease in primary care. Am J Gastroenterol 2007;102:1454-60.

57. Rashtak S, Ettore MW, Homburger HA, Murray JA. Combination testing for antibodies in the diagnosis of celiac disease. Alim Pharmacol Ther 2008;28:805-13.

58. Naijer AJ, Hernandez L, Ciaccio EJ, et al. Comparison of commercially available serologic kits for the detection of celiac disease J Clin Gastroenterol 2009;43:225-32. 


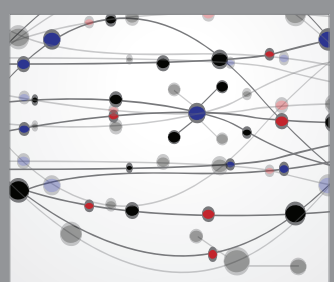

The Scientific World Journal
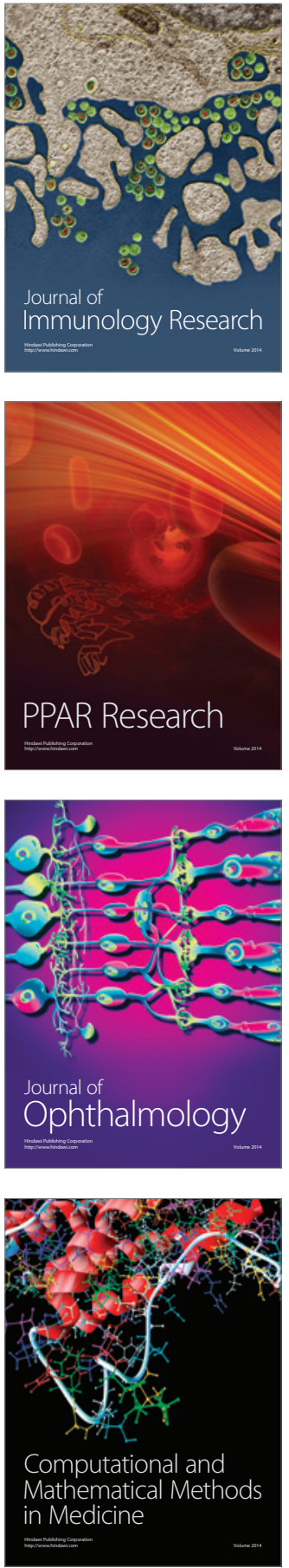

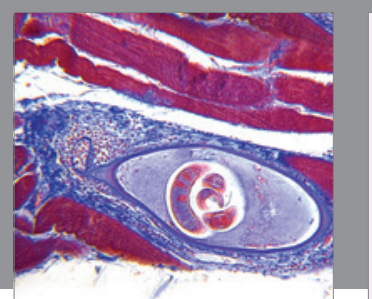

Gastroenterology Research and Practice

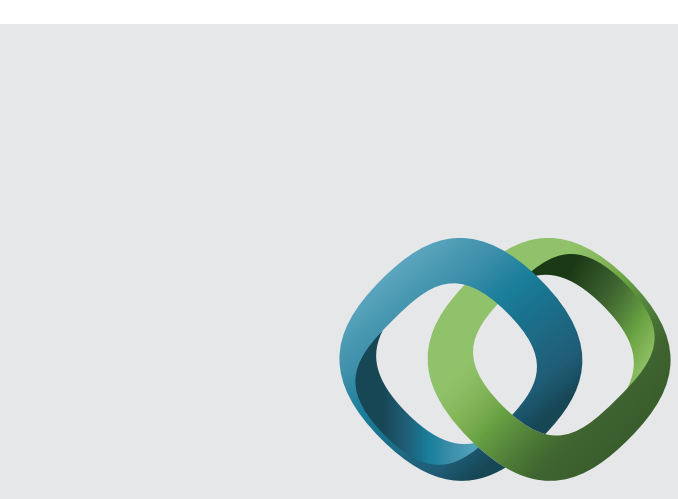

\section{Hindawi}

Submit your manuscripts at

http://www.hindawi.com
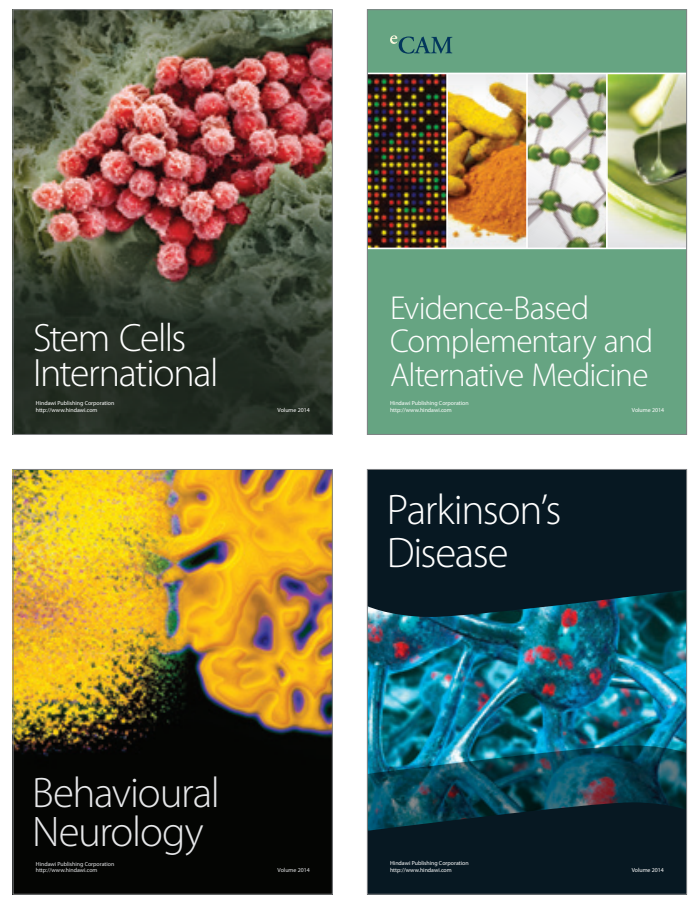
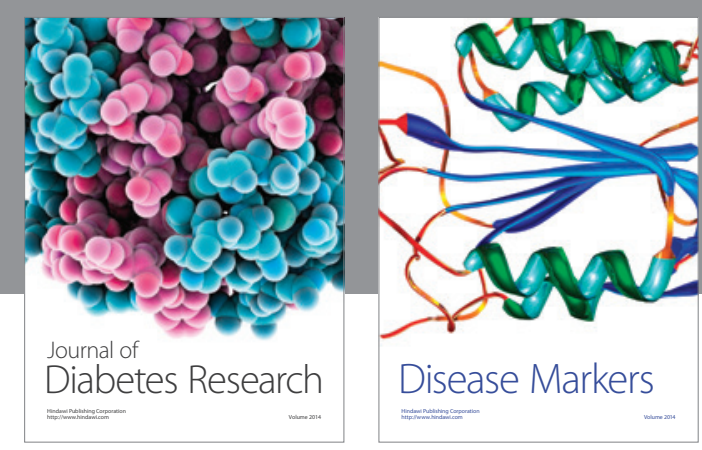

Disease Markers
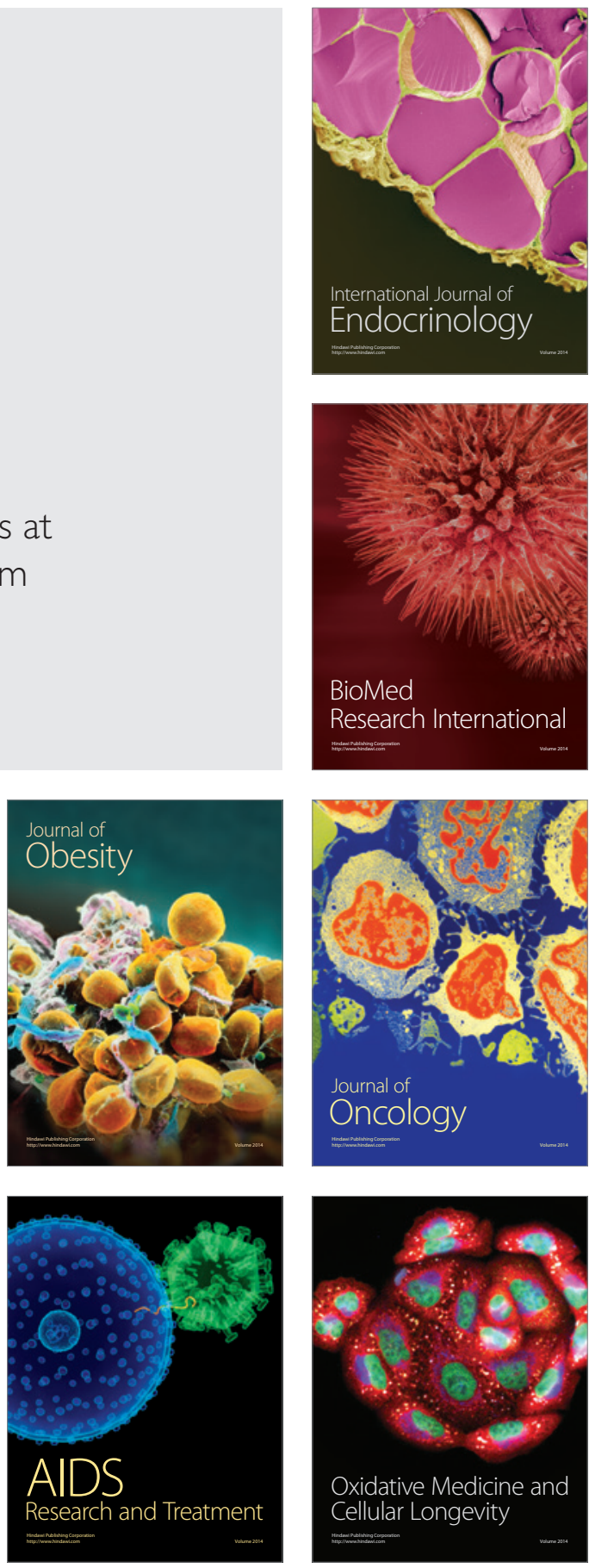